\title{
Helping factors \\ in an outdoor adventure program
}

Journal of Social Work $0(0) 1-19$

(C) The Author(s) 2019

Article reuse guidelines: sagepub.com/journals-permissions DOI: 10.1 I77/I4680I73|9863708 journals.sagepub.com/home/jsw

@SAGE

\author{
Virginie Gargano $(\mathbb{D}$ and \\ Daniel Turcotte \\ Université Laval, Québec, Canada
}

\begin{abstract}
- Summary: A number of studies have addressed outdoor and adventure programs over the past 50 years. Despite empirical evidence that demonstrates the personal benefits of group interventions, research investigating the mechanisms responsible for these effects is scarce. This is particularly so for groups in natural outdoor and adventure settings. There is therefore a need to improve our understanding of the processes involved. This research focused on personal and interpersonal processes that occurred during an outdoor group expedition. Semi-structured interviews were undertaken with 23 subjects aged between 17 and 21 who had participated in an 18-day expedition. The data are examined through a theoretical framework known as "helping factors" often used when studying benefits of a group intervention.

- Findings: The results show that participation in the program promoted selfunderstanding, interpersonal learning, socializing techniques, and cohesion. Altruism, imitative behavior, universality, and imparting information were also important. As for existential factors, corrective recapitulation of the family, catharsis, and hope, these were rarely mentioned if not absent.

- Applications: The results give a better understanding of the helping factors in such programs and of their potential role in the group process, as well as their application in social work practice.
\end{abstract}

\section{Keywords}

Social work, group, group work, critical incident analysis, education, human growth and development, qualitative research, helping factors

\section{Corresponding author:}

Virginie Gargano, Faculty of Social Sciences, Université Laval, 1030 avenue des Sciences Humaines, Québec GIV 0A6, Canada.

Email: virginie.gargano.I@ulaval.ca 
While outdoor activities have been used for more than 100 years in the field of social work and education (Gass, Gillis, \& Russell, 2012), they have recently become more popular in the literature, as demonstrated by the numerous programs evaluated in natural outdoor and adventure settings (Ewert \& Sibthorp, 2014; Tucker \& Norton, 2013). Recent empirical studies have highlighted some personal and interpersonal benefits: self-confidence, social skills, feelings of personal efficacy (Mutz \& Müller, 2016), motivation to attend school, and connection with nature (Bettmann, Russell, \& Parry, 2013; Braun \& Dierkes, 2016; Tucker, Javorski, Tracy, \& Beale, 2013). However, data regarding active elements of the process leading to these outcomes remain rudimentary. Despite empirical evidence that demonstrates the effectiveness of group interventions, research investigating the mechanisms responsible for these effects is scarce (Brouzos, Vassilopoulos, \& Baourda, 2015; Davies, Burlingame, Johnson, Gleave, \& Barlow, 2008). This is particularly so for groups in natural outdoor and adventure settings (Rothwell, Siharath, Badger, Negley, \& Piatt, 2008; Schoel \& Maizell, 2002). In this article, we investigate group processes in an outdoor adventure education (OAE) experience.

\section{Literature review}

\section{Historical background}

Recognized for its large diversity of approaches and methods, social work offers a variety of interventions that concern psychosocial development (Turcotte \& Lindsay, 2014). OAE programs are one such approach.

The first initiatives in OAE programs occurred during the early 1900s in various organizations that used leisure activities, now acknowledged as an early form of social work with groups, as a means for human development. Notable examples were settlement houses, community action centers, and leisure organizations, such as holiday camps, operating in natural environments (Malekoff, 2004; Turcotte \& Lindsay, 2014). As play and active participation were recognized as factors in the development of personal and collective responsibility, immersion in natural environments with a group of peers was considered a means to form better citizens (Mishna, Michalski, \& Cummings, 2001). Between 1930 and 1960, the development of psychosocial practices in clinical settings, the desire for professional recognition among social workers, and the doubts concerning the therapeutic nature of approaches based on play diminished the popularity of outdoor-based programs in favor of more conventional practices (Turcotte \& Lindsay, 2014).

Nevertheless, OAE programs survived this operational phase in educational, community, and institutional organizations. They became the subject of various studies in both education and social sciences (Panicucci, 2007; Priest \& Gass, 2018), thus explaining the variety of designations associated with them. 


\section{Definition}

Several definitions are used to specify therapeutic or educational interventions that rely on nature and adventure: adventure-based education (Prouty, 2007), adventure education (Bailey, 1999), adventure therapy (Bandoroff \& Newes, 2004), outdoor education (Priest \& Gass, 2018), wilderness adventure therapy (Bowen, Neill, \& Crisp, 2016), wilderness therapy (Davis-Berman \& Berman, 1994), etc. According to Ewert and Sibthorp (2014), an intervention that relies on nature and adventure, whether educative or therapeutic, is defined as an OAE program if it has the following elements: group activities in the natural environment, specific objectives for each activity guided by a leader, and an emphasis on the development of social relationships through adventure activities that include aspects of risk and challenge.

\section{Outcomes and active elements}

A number of studies have attributed positive outcomes to OAE programs. At the personal level, notable outcomes include self-esteem and self-confidence (Bowen et al., 2016; Michalski, Mishna, Worthington, \& Cummings, 2003), self-perception (Garst, Scheider, \& Baker, 2001), the feeling of personal efficacy, and a better connection with nature (Braun \& Dierkes, 2016). At the interpersonal level, outcomes include the development of social skills (Stott \& Hall, 2003), and feelings of cohesion and efficiency within the group (Hatch \& McCarthy, 2005). Although several authors have called for a better understanding of the processes that give rise to these effects (Bettmann et al., 2013; Russell \& Phillips-Miller, 2002), certain elements have been listed as predictors of positive outcomes (McKenzie, 2003; Panicucci, 2007). These include experimenting with challenge and success through risk-taking (McKenzie, 2003; Priest, 1999), adaptive dissonance (Nadler, 1993; Russell \& Phillips-Miller, 2002), and the development of a supportive community (Deane \& Harré, 2014; Scheinfeld, Rochlen, \& Buser, 2011).

According to Walsh and Golins (1976), experimenting with challenge and success through risk-taking in a supportive physical and social environment with positive feedback tends to create a favorable learning context. Despite the rarity of empirical studies that support it, the model has attracted considerable interest (McKenzie, 2003; Sibthorp, 2003).

Adaptive dissonance involves two components: (a) a destabilizing context in which participants are immersed (e.g. forests, weather conditions, unfamiliar environments, unknown peer groups) and (b) challenging activities. Participants must call upon personal resources that are seldom used, resort to new adaptation strategies, and develop adjustment mechanisms (McKenzie, 2003; Russell \& Phillips-Miller, 2002; Tucker et al., 2013).

As for the development of a support community (Russell \& Phillips-Miller, 2002; Scheinfeld et al., 2011), the presence of a structure of collaboration and support that arises from participant interdependence enhances the use of cognitive 
and psychological spheres (Rothwell et al., 2008) and creates a laboratory of interpersonal experiences (Deane \& Harré, 2014).

\section{Helping factors}

Although certain studies have focused on aspects such as acceptance by peers (Garst et al., 2001), mutual confidence (Scheinfeld et al., 2011), cohesion, and learning by imitation (Deane \& Harré, 2014), group processes have received little attention in the literature on OAE programs (Rothwell et al., 2008; Schoel \& Maizell, 2002). Much remains to be understood concerning the role of group processes and interpersonal interactions during such programs.

An early review of literature on groups by Corsini and Rosenberg (1955) revealed certain catalysts for change during group processes. Since then, understanding has deepened through studies of individuals' perceptions, often through a classification of factors into predetermined categories (Brouzos et al., 2015). This has revealed the presence of factors and their characteristics in different types of groups including therapeutic, supportive, counseling, and educational, thus enlarging their relevance from therapeutic to psychosocial (Shechtman, 2007).

Several models of group processes exist (Bloch \& Crouch, 1985; Reid, 1997; Turcotte \& Lindsay, 2014; Yalom \& Leszcz, 2005). Yalom and Leszcz (2005), for example, presented a conceptual framework of 11 important factors that can play a role in group processes. These were known as therapeutic factors (Bloch \& Crouch, 1985; Yalom \& Leszcz, 2005) or helping factors (Schwartzberg, 1994). Research shows that these are linked to group outcomes (Shechtman, 2007). Helping factors, acting interdependently, allow individual members to benefit by participating in the group (Bloch \& Crouch, 1985).

The presence of helping factors is influenced by the age and experience of participants but also by the type of group and its stage of development (Lindsay, Roy, Turcotte, \& Montminy, 2006; Yalom \& Leszcz, 2005). Although originally used in psychotherapy, the model of helping factors is now recognized in the field of social work, where it has been adapted to suit the needs of the client population but also to study the mechanisms occurring within groups (Tosone, 2009). Classification systems vary according to the type of group (Lindsay et al., 2006) and several framework models of helping factors exist (Bloch \& Crouch, 1985; Reid, 1997; Turcotte \& Lindsay, 2014; Yalom \& Leszcz, 2005). The model of 11 helping factors proposed by Yalom and Leszcz (2005) (Table 1) is now, however, widely accepted and frequently used as a reference framework (Lese \& Macnair-Semands, 2000; Magen \& Glajchen, 1999). In light of this and given the exploratory nature of the present study, this framework was used to examine helping factors in an OAE program. 
Table I. Description of the Yalom and Leszcz (2005) helping factors.

\begin{tabular}{ll}
\hline Helping factor & Definition \\
\hline Altruism & Mutual assistance between group members, benefiting those \\
& who provide assistance, as well as those who receive it. \\
Individuals feel valued when giving. \\
The expression of emotions within the group. \\
The result of forces that urge members of a group to unite in a \\
context of solidarity. Members feel supported and accepted \\
Cohesion \\
within the group. \\
Recognition of the group as a metaphor for the family unit. The \\
group approach allows participants to experience past family \\
of the primary family group \\
dynamics (confrontation with authority figures, peer \\
relations, revelation of the self, intimacy, and competition). \\
Recognition of personal behaviors and attitudes through \\
feedback provided by members of the group, requiring \\
openness from participants. \\
Recognition of personal responsibility for one's actions and \\
decisions. Participants are mainly responsible for the actions \\
required when confronting challenges, regardless of the \\
support they receive. \\
The optimism and equanimity resulting from contact with \\
others who are experiencing a similar situation. \\
Interpersonal relationship quality generated through mutual \\
feedback in a safe and structured context of \\
experimentation. \\
The behavioral influence of instructors and members regarding \\
preferred communication patterns and attitudes. \\
Instructions, suggestions, and advices shared by participants \\
and instructors. \\
Contact with others mitigates feelings of isolation and \\
promotes interpersonal identification. Reduces feelings \\
of isolation in individuals upon realizing that others are \\
experiencing a similar situation.
\end{tabular}

\section{Group types and helping factors}

In order to explore how the emergence of helping factors is influenced by the type of group and by the life problems of the participants, some studies have classified helping factors in order of importance (Lindsay et al., 2006). A selection of studies is briefly presented here to highlight the results found in the literature.

In studies of therapy groups, self-understanding (Ahmed, Abolmagd, Rakhawy, Erfan, \& Mamdouh, 2010; Reimer \& Mathieu, 2006; Roy, Turcotte, Montminy, \& Lindsay, 2005; Sribney \& Reddon, 2008), cohesion, catharsis (Ahmed et al., 2010; 
Reimer \& Mathieu, 2006; Sribney \& Reddon, 2008), and interpersonal learning (Ahmed et al., 2010; Roy et al., 2005) were at the top of the list. Among the least important factors were found corrective recapitulation of the family (Ahmed et al., 2010; Roy et al., 2005), imitative behavior (Ahmed et al., 2010; Reimer \& Mathieu, 2006; Sribney \& Reddon, 2008), and imparting information (Sribney \& Reddon, 2008). These studies were undertaken with individuals experiencing various life problems: conjugal violence (Roy et al., 2005), addiction (Ahmed et al., 2010), and sexual delinquency (Reimer \& Mathieu, 2006; Sribney \& Reddon, 2008).

In support groups, cohesion, existential factors, and hope were dominant among cancer patients (Magen \& Glajchen, 1999) and also among relations of hospital patients (Oliveira, Medeiros, Brasil, Oliveira, \& Munari, 2008), whereas imitative behavior was almost or completely absent.

As for counseling and psychoeducation groups, hope and universality (Lara et al., 2004; Pan \& Lin, 2004), imparting information (Lara et al., 2004; Schwartz \& Waldo, 1999), and socializing techniques (Schwartz \& Waldo, 1999; Shechtman, Bar-el, \& Hadar, 1997) were the most frequent factors. Learning by imitation and existential factors were less important (Pan \& Lin, 2004) or absent (Schwartz \& Waldo, 1999). Some of these studies concerned adolescents and young adults either without particular problems or whose problems were not mentioned (Pan \& Lin, 2004; Shechtman et al., 1997). Other studies focused on groups with problems of depression (Shechtman et al., 1997) and conjugal violence (Schwartz \& Waldo, 1999).

Any comparison of these studies should be undertaken in the light of certain methodological considerations. First, the chosen instruments of measure varied from one study to another. Some studies used the "Yalom Questionnaire" (Ahmed et al., 2010; Magen \& Glajchen, 1999; Reimer \& Mathieu, 2006; Sribney \& Reddon, 2008) while others favored the "Critical Incident Questionnaire" (Schwartz \& Waldo, 1999) or the "Therapeutic Factor Scale" (Pan \& Lin, 2004). Furthermore, cultural differences between the populations under study are likely to influence the results (Ahmed et al., 2010; Lara et al., 2004; Oliveira et al., 2008; Pan \& Lin, 2004; Shechtman et al., 1997). Some researchers recommend consideration of the relative importance of the helping factors as perceived by the intervener (Lindsay, Roy, Montminy, Turcotte, \& Genest-Dufault, 2008; Pan \& Lin, 2004). Others, in suggestions for future studies, emphasize the importance of taking into account the development stage of the group (Magen \& Glajchen, 1999; Roy et al., 2005).

\section{Method}

\section{Research objectives}

The objective was to explore the nature, importance, and role of helping factors that emerged during an OAE program. The study, based on a socio-constructivist vision, attempted to answer two questions. (a) Which helping factors are at work in 
a group intervention in a natural outdoor and adventure setting? (b) What is their relative importance according to the participants?

\section{Study population}

The study population was composed of college students enrolled in the optional "Experiential Outdoors" course offered by the postsecondary college Cégep de l'Outaouais. The 40 students enrolled came from various pre-university and technical programs. Within this new cohort, 23 took part in the study, 13 females and 10 males, all aged between 17 and 21 years (average $=18$ years).

For the purpose of recruitment, information concerning the research project was presented at a meeting at the end of the expedition. Those who expressed interest were later contacted individually by an independent interviewer employed for the task.

\section{Study context}

The program was an 18-day expedition in the Outaouais region (Québec, Canada) and led by an experienced teaching team. The expedition had pedagogic objectives of knowledge acquisition in the field of natural sciences but also psychosocial objectives, notably on personal and interpersonal levels. A multi-activity format (Table 2) was adopted for the expedition to achieve these objectives. Moreover, the educational process was anchored in the fundamentals of experiential learning.

\section{Data collection and analysis}

Participants completed a consent form before taking part in the study. They were informed of their right to respond freely and to remove themselves from the process at any time. They were also informed of measures employed to ensure data confidentiality. For this purpose, participants, interview grids, and audio material were identified by codes. All materials were secured in a locked cabinet and computer data were protected with a modified password.

Table 2. Description of activities.

\begin{tabular}{ll}
\hline Day & Activities \\
\hline $1-3$ & Cycling \\
$4-5$ & Hiking \\
6 & Canoeing techniques \\
$7-9$ & Canoeing expedition and $1 / 2$ day caving \\
$10-11$ & Solo camping \\
12 & 9 km run and climbing techniques \\
13 & Solo canoeing and climbing \\
14 & Sea kayaking and land art \\
15 & Snorkeling \\
$16-18$ & North canoe expedition and $14 \mathrm{~km}$ run \\
\hline
\end{tabular}


The technique chosen as reference for data collection was that of critical incidents (Flanagan, 1954). Data were collected during semi-guided interviews centering on the chronological reconstruction of the participant's experience. The interview guide consisted of the following questions related to each activity (Table 2). Of the events that occurred during the activity, which one do you feel was the most important for you personally? Describe the event: what took place, the group members involved, and their reactions. Why was this important to you? These interviews lasted about two hours and were undertaken in person and then transcribed for analysis.

A preliminary examination of the data was undertaken to identify critical incidents that emerged from each activity. Then, according to the procedure of thematic analysis, content was organized using NVivo software (version 10.0), and each interview was analyzed relative to the predetermined helping factors. The process was mainly deductive (Padgett, 2017). Definitions of helping factors proposed by Yalom and Leszcz (2005), along with key codes, descriptions, and examples, were used to classify the data (Rubin \& Babbie, 2011). However, when significant data corresponded to no existing category, a new category was created (Padgett, 2017). One important example of a category that emerged is selfunderstanding.

To assure reliability, each interview was examined independently and coded in the same way. Encoding was undertaken throughout by the principal researcher alone. However, as suggested by Saldaña (2013), the co-authors held frequent exchanges throughout the process of codification and analysis of the data in order to maintain consistency.

According to the socio-constructivist vision adopted for this study, strategies concerning reliability aim to grasp a multitude of subjective realities (Rubin \& Babbie, 2011). Qualitative saturation was achieved when further data added little to the accumulated analysis. This assured a collective perception with regard to the lived experiences.

\section{Results}

Analysis of the transcripts from the 23 interviews revealed 683 references to helping factors. The factors that emerged most often were the following: selfunderstanding $(28.7 \%)$, cohesion $(20.1 \%)$, altruism $(14.5 \%)$, interpersonal learning $(10.1 \%)$, and universality $(9.2 \%)$. After these came socializing techniques $(5.6 \%)$, imparting information $(5.6 \%)$, and imitative behavior $(4.5 \%)$. The others were rarely mentioned or absent: existential factors $(1.2 \%)$, corrective recapitulation of the family $(0.3 \%)$, catharsis $(0.3 \%)$, and hope $(0 \%)$. Selected quotes by participants are presented to illustrate helping factors.

Self-understanding was mentioned by all the participants $(23 / 23)$. The experience taught them to better understand their strengths and limits, notably as a result of the numerous challenges to be faced and the multitude of interactions with other 
participants. This factor seemed to be closely linked to the helping factors of interpersonal learning and socializing techniques.

I learnt to overstep my limits and also that we are all different. Usually, if you don't agree with others, you can just leave. Here, you are stuck with them. You have to keep an open mind, to listen to what they want to say and to avoid getting angry when you don't agree. You realize that you are not alone in the world. This helped me grow up. (Joshua)

The helping factors of interpersonal learning and socializing techniques were mentioned by almost all the participants (21/23 and 20/23, respectively). While undertaking various tasks, participants had to adapt to the group and practice patience and tolerance, all of which influence the development of these helping factors. The following comment illustrates the natural way in which interpersonal learning arose during the expedition. "You're with a group of individuals whom you don't necessarily get along with. For 18 days, you wonder how you're going to stay positive. You learn to manage your relationships with others" (Cedric).

Throughout the expedition, the participants were divided into five subgroups, in which they shared daily chores. The subgroups were modified on several occasions by random selection to give participants repeated opportunities to adapt and practice their ability to enter into social relationships. Participants had to communicate with one another and explore different practical options. In spite of tensions that can occur between members, subgroup changes encouraged personal evolution and the development of socializing techniques. "You learn without realizing you're learning. You learn how to behave with others, how to avoid hurting people when you talk to them, without sacrificing your intended message, and how to encourage people who are having trouble" (Yan).

Each time the teams were modified, the group dynamic changed. This called for adaptation. Making camp, cooking, lighting fires, such daily activities obliged the participants to socialize and work together, thus developing interpersonal cohesion. This cohesion was further encouraged by the challenges to be undertaken collectively while relying on one another despite disagreements.

A large majority of participants (20/23) mentioned a feeling of cohesion, which grew as the expedition advanced and the activities changed. The mutual help between participants produced a feeling of being accepted and of being part of a group: they felt that they were members of a "gang"; they felt as a "family."

The emergence of this helping factor was linked to altruism, which also appears in the comments of a majority of participants (19/23). They claimed that they had to consider the needs of others. The challenges to be overcome, sometimes in difficult weather conditions, promoted empathy and required mutual help. "If it rained and a friend of mine didn't have a coat, I would share the liner from my own coat for protection. It's like nature gave us these challenges so we could help each other" (Jennifer). 
The adverse conditions (weather, mosquitos, and heavy loads to be portaged over steep trails) that promoted mutual support also created tensions within the subgroups. As success depended on solidarity, members were obliged to solve conflicts and work as a team. In these situations, helping factors acted in interdependence, especially interpersonal learning and socializing techniques. By developing respect with regard to differences during a multitude of challenges that required teamwork, individuals learnt to support and help one another.

Furthermore, the positive attitude and solidarity shown by some members encouraged others to adopt similar behaviors. The enthusiasm to participate in activities was evidence of motivation and promoted the adoption of behaviors by imitation, as for example during the snorkeling activity. "It really stuck with me, because it was cold and everybody did it. The group helped. All it takes is one or two motivated people, and the others get on board, despite the bad weather" (Karen).

As perceived by many participants (16/23), imitative behaviors had the effect of developing a positive group dynamic, marked by mutual help and support during the activities. For them, these behaviors were linked to the reality of living through similar conditions and feeling united in the face of adversity. Adverse weather conditions plus the tasks required to fulfill basic needs were destabilizing. Involvement and energy were required but contributed to the promotion of proactive attitudes and to the emergence of a feeling of universality felt by many (16/23).

The diversity of the proposed activities during the expedition gave participants the chance to share information and knowledge in order to overcome the challenges. While exploiting the talents of everyone, participants supported each other by exchanging information. For some participants $(14 / 23)$, this helping factor revealed itself as a key element at different stages of the expedition.

The fact that the activities were undertaken in groups, that helps to feel confident and to surpass oneself. Everyone is there to help one another. For example, if you are really good on a bicycle but not so good in a canoe and it is the opposite for someone else, then we can help each other with strengths and shortcomings. (Stephany)

Certain helping factors were mentioned by few participants. These include existential factors $(4 / 23)$, corrective recapitulation of the family $(2 / 23)$, and catharsis $(1 / 23)$. Hope $(0 / 23)$ was not mentioned. Existential factors arose during the 48 hour solo camping activity. Solitude and challenge promoted awareness of personal strengths and limitations but also of the importance of the group. Alone, the participants realized that they had to rely on themselves and that their fate was in their own hands.

As for corrective recapitulation of the family, two participants revealed that the experience touched them with regard to their past. The following example illustrates the point well.

When I was young, I was different and so excluded socially. In everyday life, I was afraid of relationships. [The 18 day expedition], it reminded me of my childhood, 
because I was forced to work with others. During the expedition, I realized that I liked being in contact with people. I was happy to find this aspect in myself. (Louis)

With regard to catharsis, only one participant mentioned this helping factor. The emergence of this helping factor was related to a realization of certain attitudes with regard to the group.

Apart from helping factors, there emerged from the analysis of respondents' comments certain active elements identified in other studies on activities in natural outdoor and adventure settings. These included experimenting with challenge and success through risk-taking, adaptive dissonance, and the creation of a supportive community. Activities that required a significant physical effort highlighted the notion of challenge and success in the comments of a majority of participants (18/23).

Every day, you are completely immersed in wilderness. At the end of the day, you ache all over because you have paddled all day. You know that your body is tired, but at the same time you say to yourself "wow, we did it." (Sam)

For these participants, being able to achieve the level of effort required and the subsequent satisfaction were linked to the well-being felt in the natural environment. Moreover, the variety of activities allowed them to live a multitude of challenges and achievements while putting their competencies to the test. As for dissonance and adaptation, most respondents (16/23) mentioned it. "When you are in nature, it is you that has to adapt. Everything disturbs you, affects you; everything is abnormal. At the same time, you feel well; you develop a new comfort zone" (Sam).

This destabilization was perceived as an agent for personal development. For the participants, the frequent change of teams, the weather conditions, the fact of living in nature for 18 consecutive days, and the diversity of the activities all demanded a constant adaptation, thus encouraging them to surpass themselves on both personal and interpersonal levels. For these same reasons, the community of mutual help was an important determinant during the expedition for many participants $(18 / 23)$.

You push back your limits in different sports. The fact that you force yourself, the result is that you are no longer yourself; a façade falls. Everyone is more open with others. Because you are in nature, you are more insecure and so everyone helps and supports one another. (Annie)

\section{Limits}

The results of this study must be interpreted in the light of certain limits. First, it is essential to note that some bias might arise due to social desirability. As the principal researcher was also a lead teacher, it is possible that participant comments 
were influenced by a desire, whether conscious or not, to portray a positive image of their experience. To minimize this bias, all interviews were conducted by an independent person not related to the research study. The double role of the researcher may also lead to a bias during the analysis and interpretation. The frequent exchanges between the co-authors, however, should limit this bias. Furthermore, a major advantage of the double role is a direct understanding of the experience under study (Padgett, 2017). Other aspects that might affect the results include the type of cohort, the variable levels of individual outdoor competencies, the frequent changes in subgroups, and the numerous interventions by leaders. With these aspects in mind, considering both the small number of participants and the type of program, prudence is advised with regard to the direct transferability of the results.

\section{Discussion}

The purpose of this study was to investigate the presence of helping factors in an OAE program with a nonclinical population. In fact, participants' comments contained numerous references to these factors, of which several appeared in interdependence as mentioned in other relevant studies (Bloch \& Crouch, 1985; Yalom \& Leszcz, 2005).

During this study, three helping factors were mentioned by virtually all the participants: self-understanding, interpersonal learning, and socializing techniques. Of these, the first was the most frequently cited. In other studies, selfunderstanding was found to be among the most important factors in therapy groups (Ahmed et al., 2010; Reimer \& Mathieu, 2006; Roy et al., 2005; Sribney \& Reddon, 2008) and in counseling groups (Pan \& Lin, 2004). On the other hand, in the support group studied by Magen and Glajchen (1999), self-understanding was low in the ranking.

With regard to interpersonal learning and socializing techniques, few ties between results of the present study and those found in the literature permit any conclusions. Both helping factors did however appear among the most important in the study by Shechtman et al. (1997) undertaken with two nonclinical groups. Interpersonal learning was also one of the most dominant helping factors in the study by Ahmed et al. (2010) while that of Schwartz and Waldo (1999) found socializing techniques to be prevalent. The former study concerned participants with substance addiction, while the latter involved participants with behavior of conjugal violence. These studies did not identify any particularities of the group experience that might lead to these helping factors. In the present study however, their strong presence seems related to the multitude of adventure activities, to the interpersonal commitment required to complete the proposed tasks, and to the frequent modifications of the subgroups.

The results show that the situations of challenge and vulnerability encouraged participants to use internal resources and to develop interpersonal relationships. These conditions contributed to the emergence of certain helping factors such as 
altruism, cohesion, and universality. According to the literature, these appeared in different group types. Altruism, for example, was found to be one of the most important helping factors in a support group for cancer patients (Magen \& Glajchen, 1999). In other studies, however, this helping factor was of little importance.

The results for cohesion are reflected in the remarks of Yalom and Leszcz (2005), who asserted that the degree of cohesion is influenced by risk-taking. In the literature, cohesion appeared as an important helping factor in support groups (Magen \& Glajchen, 1999; Oliveira et al., 2008), in therapy groups (Ahmed et al., 2010; Reimer \& Mathieu, 2006; Sribney \& Reddon, 2008) and in psychoeducation groups (Pan \& Lin, 2004; Schwartz \& Waldo, 1999). Except for the groups in the study by Pan and Lin (2004), all of these groups were made up of participants with particular life problems: illness, sexual delinquency, substance addiction, and violence.

Universality appeared notably in support groups (Magen \& Glajchen, 1999), in therapy groups (Roy et al., 2005), and in psychoeducation groups (Lara et al., 2004; Pan \& Lin, 2004). In all these studies except the last, participants had particular life problems: cancer, violent behavior, and depression. For the study by Pan and Lin (2004), participants were nonclinical. According to Yalom and Leszcz (2005), universality was often reliant on emotions felt by the participants, notably feelings of shame and guilt. During this expedition however, the emergence of altruism, cohesion, and universality depended more on the fact that the participants were confronted with the same challenges, rather than on a collective clinical problem.

The results do highlight the interdependence of these three helping factors for a group immersed in nature. Although the environment itself provided multiple occasions to develop cohesion and universality, social interactions also seem to have played a significant role. Altruism, on the other hand, may have been encouraged by the large diversity of activities that encouraged participants to help others.

With regard to imitative behavior, this helping factor appeared as a result of modeling between participants. According to Roy et al. (2005), the age of the participants might explain such results. Their work showed a relation between age and the presence of this helping factor. Young participants attributed more importance to imitative behavior than older participants.

As for imparting information, it appeared in the upper ranks of two studies, one concerning a support group (Oliveira et al., 2008), the other involving a therapy group (Roy et al., 2005), but was in the lower ranks in other studies focused on similar group types (Ahmed et al., 2010; Oliveira et al., 2008; Reimer \& Mathieu, 2006; Sribney \& Reddon, 2008). In studies produced by Lara et al. (2004) and by Schwartz and Waldo (1999) on psychoeducation and counseling groups, imparting information was found to be among the most important helping factors, a result that might be explained by the type of group under study. Emerging through the exchange of advice and information concerning challenges faced by participants (Yalom \& Leszcz, 2005), this helping factor was of high importance in groups of an educational nature. In the case of the present study, the helping factor of imparting 
information emerged through the sharing of knowledge about both the adventure activities themselves and the organization of the group in the natural environment.

The absence of certain helping factors in this study should be interpreted in the light of some particular aspects. According to the literature, hope, for example, frequently emerged in an atmosphere of intimacy (Pan \& Lin, 2004; Schwartz \& Waldo, 1999) and when participants were in contact with others experiencing similar life problems (Yalom \& Leszcz, 2005). In the present OAE program, the educational context, the multiple changes in subgroups, and the absence of a common life problem may help explain the absence of this helping factor. The same might be said for catharsis, which emerges in particular in groups with participants experiencing problems of depression (Lara et al., 2004), of substance addiction (Ahmed et al., 2010), and of sexual delinquency (Reimer \& Mathieu, 2006; Sribney \& Reddon, 2008). The first concerned a support group, the others therapy groups. In all these groups, catharsis was a major helping factor, in stark contrast with the present study which was educational by design. The same aspects of the present program under study may explain the absence of corrective recapitulation of the family. Although often minor helping factors, they have occurred in support groups (Magen \& Glajchen, 1999) and in therapy groups (Ahmed et al., 2010; Reimer \& Mathieu, 2006; Roy et al., 2005; Sribney \& Reddon, 2008).

Apart from helping factors, the results also highlight some active elements of an OAE program. As mentioned by Martin and Priest (1986), experimenting challenge and success implies risk-taking. During the program under study, this was related to the physical effort required in the context of numerous challenges in an outdoor environment. Another element was adaptive dissonance. Finding themselves in unfamiliar situations and in demanding outdoor environments, participants were forced to engage their personal and interpersonal resources in order to adapt, thus corroborating remarks by other authors (McKenzie, 2003; Russell \& Phillips-Miller, 2002; Tucker et al., 2013). As mentioned by Rothwell et al. (2008), the element of a support community, arising from mutual help and interdependence, encourages participants to collaborate. In this study, these conditions were provoked by numerous activities that required teamwork but also by the destabilization due to the harsh natural environment. The results thus support some previously recognized aspects concerning these active elements of OAE programs.

Compared to other studies on helping factors however, the present study is particular. Considering the relevant literature as a whole, dominant helping factors vary according to the group type, the development stage of the group, and the life problems experienced by the participants (Tosone, 2009; Yalom \& Leszcz, 2005). In this study on a group of young nonclinical participants, the diversity and complexity of the collective activities in a demanding outdoor environment seem to have played a role in the emergence of the major helping factors. Activities that nourished feelings of interdependence and interpersonal commitment seem to have been particularly important. Although the processes that underlie the emergence of helping factors remain unclear (Lindsay et al., 2008), the study does contribute to the overall understanding of group interventions. Furthermore, some of the 
features of the OAE program, such as complex and challenging activities that require team work and mutual aid, may be of interest for more conventional interventions, even in groups of more clinical nature.

\section{Conclusion}

The aim of this study was to understand the place of helping factors and their importance in an OAE program. The results confirm their presence and bring to light the nature of their interactions.

The helping factors of self-understanding, cohesion, altruism, interpersonal learning, and universality were mentioned most often. Socializing techniques, imparting information, and imitative behavior were also important. As for existential factors, corrective recapitulation of the family, catharsis, and hope, these were rarely mentioned if not absent.

A characteristic of this program was the level of destabilization and dissonance experienced by participants as a result of adverse weather, unfamiliar environments, and multiple challenges. The diversity of activities and the multitude of interactions created by modifications to the subgroups acted as catalysts for the emergence of helping factors. The collective experience appears to be a key element during such a program.

In the context of social work practice with groups, this type of OAE intervention might be considered an interesting option to enlarge its scope. Adventure activities in the natural environment may be particularly appropriate for participants with special needs or who are resistant to conventional psychosocial interventions. The levels of destabilization and dissonance, two key features, should be adjusted according to the type of group, the problems faced by the participants, and their development stage. The same applies to the choice of activities. Nevertheless, with judicious planning, helping factors can be expected to emerge thus contributing to both group and individual processes in a positive manner.

Further research work is however required to better understand the processes leading from lived experience to final outcomes. In order to promote and conceive nature and adventure programs, and optimize the benefits for participants, understanding these processes is essential. Outstanding questions concern, for example, the processes in groups experiencing particular problems or with participants at different development stages.

During times of change in societal values, the challenge in social work is to find ways for participants to live group experiences that promote action but also an evolution within their personal lives. In the light of this study, undertaking group work in nature and adventure settings could be a contemporary and innovative option.

\section{Ethics}

Ethical approval for this project was given by the Ethics Committee of Université Laval under the case number 2015-015/13-03-2015. 


\section{Funding}

The authors received no financial support for the research, authorship, and/or publication of this article.

\section{Acknowledgements}

We would like to thank Dr David Booth for his outstanding support in translation of this article. We also thank the Cégep de l'Outaouais for their support in this research, the research assistants, and all the research participants, who made this study possible.

\section{ORCID iD}

Virginie Gargano (D) https://orcid.org/0000-0002-7556-405X

\section{References}

Ahmed, S., Abolmagd, S., Rakhawy, M., Erfan, S., \& Mamdouh, R. (2010). Therapeutic factors in group psychotherapy: A study of Egyptian drug addicts. Journal of Groups in Addiction \& Recovery, 5(3-4), 194-213. doi:10.1080/1556035X.2010.523345

Bailey, J. (1999). A world of adventure education. In J. C. Miles \& S. Priest (Eds), Adventure programming (pp. 39-24). State College, PA: Venture.

Bandoroff, S., \& Newes, S. (2004). Coming of age: The evolving field of adventure therapy. Boulder, CO: Association for Experiential Education.

Bettmann, J. E., Russell, K. C., \& Parry, K. (2013). How substance abuse recovery skills, readiness to change and symptom reduction impact change processes in wilderness therapy participants. Journal of Child and Family Studies, 22(8), 1039-1050. doi:10.1007/ s10826-012-9665-2

Bloch, S., \& Crouch, E. (1985). Therapeutic factors in group psychotherapy. In J. L. Delucia-Waak, D. A. Gerrity, C. R. Kaloner, \& M. T. Riva (Eds), Handbook of group counseling and psychotherapy (pp. 39-228). Thousand Oaks, CA: Sage.

Bowen, D. J., Neill, J. T., \& Crisp, S. J. R. (2016). Wilderness adventure therapy effects on the mental health of youth participants. Evaluation and Program Planning, 58, 49-59. doi:10.1016/j.evalprogplan.2016.05.005

Braun, T., \& Dierkes, P. (2016). Connecting students to nature - How intensity of nature experience and student age influence the success of outdoor education programs. Environmental Education Research, 23(7), 937-949. doi:10.1080/13504622.2016.1214866

Brouzos, A., Vassilopoulos, S. P., \& Baourda, V. C. (2015). Therapeutic factors and members' perception of co-leaders' attitudes in a psychoeducational group for Greek children with social anxiety. The Journal for Specialists in Group Work, 40(2), 204-224. doi: $10.1080 / 01933922.2015 .1017065$

Corsini, R. J., \& Rosenberg, B. (1955). Mechanisms of group therapy: Processes and dynamics. Journal of Abnormal and Social Psychology, 51(3), 406-411. doi:10.1037/h0048439

Davies, D. R., Burlingame, G. M., Johnson, J. E., Gleave, R. L., \& Barlow, S. H. (2008). The effects of a feedback intervention on group process and outcome. Group Dynamics: Theory, Research, and Practice, 12(2), 141-154. doi:10.1037/1089-2699.12.2.141

Davis-Berman, J., \& Berman, D. (1994). Wilderness therapy: Foundations, theory and research. Dubuque, IA: Kendall Hunt. 
Deane, K. L., \& Harré, N. (2014). The youth adventure programming model. Journal of Research on Adolescence, 24(2), 293-308. doi:10.1111/jora.12069

Ewert, A. W., \& Sibthorp, J. (2014). Outdoor adventure education: Foundations, theory, and research. Champaign, IL: Human Kinetics.

Flanagan, J. C. (1954). The critical incident technique. Psychological Bulletin, 51(4), 327-358. doi:10.1037/h0061470

Garst, B., Scheider, I., \& Baker, D. (2001). Outdoor adventure program participation impacts on adolescent self-perception. Journal of Experiential Education, 24(1), 41-49. doi:10.1177/105382590102400109

Gass, M., Gillis, H. L., \& Russell, K. C. (2012). Adventure therapy: Theory, research and practice. New York: Routledge.

Hatch, K. D., \& McCarthy, C. J. (2005). Exploration of challenge courses' long-term effects on members of college student organizations. Journal of Experiential Education, 27(3), 245-264. Retrieved from https://eric.ed.gov/?id=EJ739517

Lara, M. A., Navarro, C., Acevedo, M., Berenzon, S., Mondragon, L., \& Rubi Angélica, N. (2004). A psycho-educational intervention for depressed women: A qualitative analysis of the process. Psychology and Psychotherapy: Theory, Research and Practice, 77(4), 429-447. doi:10.1348/1476083042555424

Lese, K. P., \& Macnair-Semands, R. R. (2000). The therapeutic factors inventory: Development of a scale. Group, 24(4), 303-317. doi:10.1023/A:1026616626780

Lindsay, J., Roy, V., Montminy, L., Turcotte, D., \& Genest-Dufault, S. (2008). The emergence and the effects of therapeutic factors in groups. Social Work with Groups, 31(3), 255-271. doi:10.1080/01609510801981029

Lindsay, J., Roy, V., Turcotte, D., \& Montminy, L. (2006). Therapeutic factors in the first stage of men's domestic violence groups: Men talk about universality and how it becomes operational in the group. Groupwork, 16(1), 29-47. doi:10.1921/0951824X.16.1.29

Magen, R. H., \& Glajchen, M. (1999). Cancer support groups: Client outcome and the context of group process. Research on Social Work Practice, 9(5), 541-554. doi:10.1177/ 104973159900900502

Malekoff, A. (2004). Strenghts-based group work with children and adolescents. In C. D. Garvin, L. M. Gutiérrez, \& M. J. Galinsky (Eds), Handbook of social work with groups (pp. 227-244). New York: Guilford Press.

Martin, P., \& Priest, S. (1986). Understanding the adventure experience. Journal of Adventure Education, 3(1), 18-21. Retrieved from https://www.academia.edu/36880827

McKenzie, M. (2003). Beyond "the ouward bound process": Rethinking student learning. Journal of Experiential Education, 26(1), 8-23. doi:10.1177/105382590302600104

Michalski, J. H., Mishna, F., Worthington, C., \& Cummings, R. (2003). A multi-method impact evaluation of a therapeutic summer camp program. Child and Adolescent Social Work Journal, 20(1), 53-76. doi:10.1023/A:102146750358

Mishna, F., Michalski, J., \& Cummings, R. (2001). Camps as social work interventions: Returning to our roots. Social Work with Groups, 24(3-4), 153-172. doi:10.1300/ J009v24n03_11

Mutz, M., \& Müller, J. (2016). Mental health benefits of outdoor adventures: Results from two pilot studies. Journal of Adolescence, 49, 105-114. doi:10.1016/j.adolescence.2016.03.009

Nadler, R. S. (1993). Therapeutic process of change. In M. Gass (Ed.), Adventure therapy: Therapeutic applications of adventure programming (pp. 57-72). Dubuque, IA: Kendall/Hunt. 
Oliveira, L. M., Medeiros, M., Brasil, V. V., Oliveira, P. M., \& Munari, D. B. (2008). Use of therapeutic factors for the evaluation of results in support groups. Acta Paulista de Enfermagem, 21(3), 432-438. doi:10.1590/S0103-21002008000300008

Padgett, D. K. (2017). Qualitative methods in social work research (3rd ed.). Los Angeles, CA: Sage.

Pan, P. J. D., \& Lin, C. W. (2004). Members' perceptions of leader behaviors, group experiences, and therapeutic factors in group counseling. Small Group Research, 35(2), 174-194. doi:10.1177/1046496403260557

Panicucci, J. (2007). Cornerstones of adventure education. In D. Prouty, J. Panicucci, \& R. Collinson (Eds), Adventure education: Theory and applications (pp. 33-48). Champaign, IL: Human Kinetics.

Priest, S. (1999). The adventure experience paradigm. In J. C. Miles \& S. Priest (Eds), Adventure programming (pp. 159-162). State College, PA: Venture.

Priest, S., \& Gass, M. (2018). Effective leadership in adventure programming (3rd ed.). Champaign, IL: Human Kinetics.

Prouty, D. (2007). Introduction to adventure education. In D. Prouty, J. Panicucci, \& R. Collinson (Eds), Adventure education: Theory and applications (pp. 3-17). Champaign, IL: Human Kinetics.

Reid, K. E. (1997). Social work practice with groups: A clinical perspective (2nd ed.). Pacific Grove, CA: Brooks/Cole.

Reimer, W. L., \& Mathieu, T. (2006). Therapeutic factors in group treatment as perceived by sex offenders: A "consumers report". Journal of Offender Rehabilitation, 42(4), 59-73. doi:10.1300/J076v42n04_04

Rothwell, E. W., Siharath, K., Badger, H., Negley, S., \& Piatt, J. (2008). The emotional dynamics of a group during a challenge course experience. Journal of Adventure Education \& Outdoor Learning, 8(2), 113-131. doi:10.1080/14729670802539453

Roy, V., Turcotte, D., Montminy, L., \& Lindsay, J. (2005). Therapeutic factors at the beginning of the intervention process in group for men who batter. Small Group Research, 36(1), 106-133. doi:10.1177/1046496404270261

Rubin, A., \& Babbie, E. R. (2011). Research methods for social work (7th ed.). Belmont, CA: Brooks/Cole.

Russell, K. C., \& Phillips-Miller, D. (2002). Perspectives on the wilderness therapy process and its relation to outcome. Child and Youth Care Forum, 31(6), 415-437. doi:10.1023/ A:1021110417119

Saldaña, J. (2013). The coding manual for qualitative researchers (2nd ed.). Los Angeles, CA: Sage.

Scheinfeld, D. E., Rochlen, A. B., \& Buser, S. J. (2011). Adventure therapy: A supplementary group therapy approach for men. Psychology of Men and Masculinity, 12(2), 188-194. doi:10.1037/a0022041

Schoel, J., \& Maizell, R. S. (2002). Exploring islands of healing: New perspectives on adventure based counseling. Beverly, MA: Project Adventure.

Schwartz, J. P., \& Waldo, M. (1999). Therapeutic factors in spouse-abuse group treatment. The Journal for Specialists in Group Work, 24(2), 197-207. doi:10.1080/ 01933929908411430

Schwartzberg, S. L. (1994). Helping factors in a peer-developed support group for persons with head injury, part 1: Participant observer perspective. The American Journal of Occupational Therapy, 48(4), 297-304. doi:10.5014/ajot.48.4.297 
Shechtman, Z. (2007). How does group process research inform leaders of counseling and psychotherapy groups? Group Dynamics: Theory, Research, and Practice, 11(4), 293-304. doi:10.1037/1089-2699.11.4.293

Shechtman, Z., Bar-el, O., \& Hadar, E. (1997). Therapeutic factors and psycho educational groups for adolescents: A comparison. The Journal for Specialists in Group Work, 22(3), 203-213. doi:10.1080/01933929708414381

Sibthorp, J. (2003). An empirical look at Walsh and Golin's adventure education process model: Relationships between antecedent factors, perceptions of characteristics. Journal of Leisure Research, 35(1), 80-106.

Sribney, C. L., \& Reddon, J. R. (2008). Adolescent sex offenders' rankings of therapeutic factors using the Yalom Card Sort. Journal of Offender Rehabilitation, 47(1/2), 24-40. doi:10.1080/10509670801940367

Stott, T., \& Hall, N. (2003). Changes in aspects of students' self-reported personal, social and technical skills during a six-week wilderness expedition in Arctic Greenland. Journal of Adventure Education and Outdoor Learning, 3(2), 159-169. doi:10.1080/ 14729670385200341

Tosone, C. (2009). Group work major models: Psychodynamic model. In A. Gitterman \& R. Salmon (Eds), Encyclopedia of social work with groups (pp. 53-55). New York: Routledge.

Tucker, A. R., Javorski, S., Tracy, J., \& Beale, B. (2013). The use of adventure therapy in community-based mental health: Decreases in problem severity among youth clients. Child \& Youth Care Forum, 42(2), 155-179. doi:10.1007/s10566-012-9190-x

Tucker, A. R., \& Norton, C. L. (2013). The use of adventure therapy techniques by clinical social workers: Implications for practice and training. Clinical Social Work Journal, 41(4), 333-343. doi:10.1007/s10615-012-0411-4

Turcotte, D., \& Lindsay, J. (2014). L'intervention sociale auprès des groupes (3rd ed.). Montréal, Canada: Gaetan Morin.

Walsh, V., \& Golins, G. (1976). The exploration of the outward bound process. Denver, CO: Colorado Outward Bound School. Retrieved from https://eric.ed.gov/?id=ED144754

Yalom, I. D., \& Leszcz, M. (2005). The theory and practice of group psychotherapy (5th ed.). New York: Basic Books. 